\title{
The effect of breast-feeding duration on bone mineral density in postmenopausal Turkish women: a population-based study
}

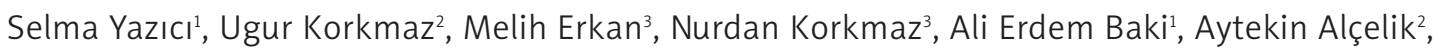
Elif Önder², Safinaz Ataoğlu ${ }^{1}$

1Physical Therapy Rehabilitation Clinic, Düzce Medical Faculty, Düzce, Turkey 2Department of Internal Medicine, Düzce Medical Faculty, Düzce, Turkey ${ }^{3}$ Department of Nuclear Medicine, Düzce Medical Faculty, Düzce, Turkey

Submitted: 25 July 2010

Accepted: 9 October 2010

Arch Med Sci 2011; 7, 3: 486-492

DOI: 10.5114 /aoms.2011.23416

Copyright (c) 2011 Termedia \& Banach

\section{Abstract}

Introduction: In the present study, we investigated the effects of breast-feeding time on bone mineral density (BMD) later in life.

Material and methods: The current study was based on a retrospective analysis of 586 postmenopausal women with a mean age of 60.8 years, who were screened for osteoporosis by dual energy X-ray absorptiometry (DXA).They were classified into 4 groups with respect to the duration of their breast-feeding as never (group 1), 1-24 months (group 2), 25-60 months (group 3), or > 60 months (group 4). Bone mineral density results for the femur neck and lumbar spine were classified into 3 groups according to WHO criteria as normal ( $T$ score $>-1.0 \mathrm{SD}$ ), osteopenia ( $T$ score -1.0 to $-2.5 \mathrm{SD}$ ), and osteoporosis ( $T$ score $<-2.5$ SD). Patients with osteopenia or osteoporosis ( $T$ score $<-1.0$ SD) were considered as having low bone mass (LBM).

Results: We found a correlation between duration of lactation and femur BMD or spine BMD in the study population $(r=0.116, p<0.005 ; r=-0.151, p=0.001$, respectively). Significant differences were found between femur BMD and spine BMD of groups in one-way ANOVA analysis ( $p=0.025, p=0.005$, respectively). Additionally, when compared with the other three groups, group 4 was older and had longer duration of menopause $(p<0.01)$. In logistic regression analysis, age and body mass index were found as independent risk factors of LBM [odds ratio: 1.084 (95\% Cl 1.031-1.141); odds ratio: 0.896 (95\% Cl 0.859-0.935)], while duration of lactation was not found as an independent predictor of LBM.

Conclusions: In this study, we have found that changes of bone metabolism during lactation had no effect on postmenopausal BMD measured by DXA. Consequently, it can be suggested that long breast-feeding duration is not a risk factor for low bone mass later in life.

Key words: breast-feeding time, bone mineral density, postmenopausal women.

\section{Introduction}

Osteoporosis is a major health problem throughout the world and the most important cause of fractures in both men and women [1]. The etiology of osteoporosis is multifactorial: constitutional factors and metabolic status are involved. In fact, modifiable factors play an important role. Lower body weight, physical inactivity, long time since menopause,

\author{
Corresponding author: \\ Dr Selma Yazıcı \\ Department of Physical \\ Medicine \\ and Rehabilitation \\ Abant Izzet Baysal \\ University Medical Faculty \\ Golkoy, 14280 Bolu, Turkey \\ Phone: 03742534656 \\ Fax: 03742535236 \\ E-mail: \\ drselmayazici@yahoo.com
}


dyslipidaemia and age over 70 years are high risk factors of low bone mineral density (BMD) [2-4]. Determination of the risk factors for osteoporosis and identification of the candidate postmenopausal women are of utmost importance for prevention of osteoporosis, optimum management, and reducing the health and human costs related to this disease.

Lactation has been recognized as a powerful stimulus for bone resorption and marked changes in calcium metabolism have been reported during lactation, related to the amount of breast milk produced, diet, and duration of lactation [5]. Moreover, during lactation, women have a period of considerable hypoestrogenaemia, which negatively affects calcium and phosphate metabolism $[6,7]$. There are reports indicating that BMD is significantly decreased (average 4-6\%) during the first 6 months of lactation followed by a $5 \%$ gain within 6 months after weaning [5, 8, 9]. However, the effect of lactation on postmenopausal BMD measurements has been controversial, with some reporting a decrease [10-13], others reporting no change [14-16], and still others reporting a beneficial effect on bone mass, later in life [17, 18]. Differences in the sample size, sites of bone measured, followup period, statistical analyses, and study design may explain the contradictory results.

To the best of our knowledge, there is only one study on the association between duration of lactation and bone mass in postmenopausal Turkish women. Therefore, in a large national sample of postmenopausal women in whom osteoporosis is highly prevalent, we aimed to investigate the associations between femoral neck and lumbar spine BMD values detected by DXA and duration of breast-feeding. Secondly, we aimed to compare femur and spine bone mass parameters of groups arranged according to duration of lactation.

\section{Material and methods}

\section{Population sample}

The current study, which was carried out in the departments of Internal Medicine and Physical Medicine of Duzce University Faculty of Medicine, was based on a retrospective analysis of 750 consecutive individuals screened for osteopenia or osteoporosis by dual energy X-ray absorptiometry (DXA) between February 2006 and May 2008. In the final analytic sample, 586 postmenopausal women (with a mean age of $60.8 \pm 8.8$ years) without any exclusion criteria were included in the study. Exclusion criteria were known chronic infectious or inflammatory disease, type I diabetes mellitus, known coronary heart disease, chronic obstructive pulmonary disease, thyroid diseases, gastrointestinal or liver disease, renal disease, neoplasm, haematological disorders, and physical inactivity. In addition, patients taking hormone replacement therapy (HRT), thyroxin, anticoagulant therapy, oestrogen, and phenytoin, known to affect bone mass, were also excluded. Postmenopausal status was determined by a "no" response to the question, "Have you had a period in the past 12 months?" Gynaecological age or duration of fertility was defined as years between menarche and menopause. Use of diuretic or antihypertensive agents and steroids, and prior medical histories, including comorbidities that might affect bone density, were also recorded. Hypertension was defined as blood pressure $\geq 140 \mathrm{mmHg}$ and/or $\geq 90 \mathrm{mmHg}$, and/or use of antihypertensive medication. Blood pressure was measured in the sitting position on the right arm, and the mean of two recordings at least 3 min apart was recorded. Body mass index (BMI) was computed as weight divided by height squared $\left(\mathrm{kg} / \mathrm{m}^{2}\right)$ [19]. Anthropometric and biochemical data were collected from the patients' physical medicine files and laboratory records included haematocrit, haemoglobin, fasting glucose and levels of cholesterol, creatinine, albumin and calcium, etc.

The Institutional Review Board of the Düzce University Faculty of Medicine approved the study. A waiver of consent was granted and patient identity was protected.

\section{Bone mineral density scans}

Bone mineral density $\left(\mathrm{g} / \mathrm{cm}^{2}\right)$ was measured for the lumbar spine $\left(L_{2}\right.$ to $\left.L_{4}\right)$ and proximal femur using a GE Lunar DPX-NT PRO (Lunar Corp, Adison, WI, USA) by DXA scanning. Bone mineral density was determined according to standard Lunar protocols. Bone mineral density was expressed in $\mathrm{g} / \mathrm{cm}^{2}$ and as peak bone mass percentage in normal subjects ( $T$ score) depending on the software used in the device. Bone mineral density results for the femur neck and lumbar spinal were classified into 3 groups according to World Health Organization criteria: normal ( $T$ score $>-1.0$ SD), osteopenia ( $T$ score -1.0 to -2.5 SD) and osteoporosis ( $T$ score $<-2.5 \mathrm{SD}$ ). Patients with osteopenia or osteoporosis ( $T$ score $<-1.0$ SD) were grouped as having low bone mass.

\section{Statistical analysis}

All continuous variables were tested for skewness. The distributions of all variables were normal. The continuous parameters were presented as mean \pm standard deviation. Participants were divided into four groups with respect to the duration of their breast-feeding as never (group 1), 1-24 months (group 2), 25-60 months (group 3), or $>60$ months (group 4). The analysis of variance (one-way ANOVA) was used to compare the BMD 
data between these groups and all pairwise comparisons between group means were applied using Scheffe post-hoc correction. Categorical variables were compared with the $\chi^{2}$ test. A multivariate logistic regression model with the enter method was used to assess the independent associations of low femur or spine BMD with duration of breast-feeding. Multinomial logistic regression analyses were also performed for BMD status according to the WHO criteria (normal, osteopenia and osteoporosis). The normal group was accepted as the reference category. Parameters obtained from univariate tests were included as covariates. Independent predictors of BMD as continuous variables were analysed by linear regression analyses to avoid any possible data loss. Categorical variables such as physical activity and smoking status were included as dummy variables. Parameters which had a significant correlation with BMD were included in the linear regression analysis. Statistical analyses were carried out using SPSS 13.0 for Windows and a $p$-value $<0.05$ was considered significant.

\section{Results}

In total, 586 subjects (mean age $60.8 \pm 8.8$ years, BMI $30.9 \pm 5.3 \mathrm{~kg} / \mathrm{m}^{2}$ ) were analysed. Demographic, clinical and laboratory variables of four groups according to duration of breast-feeding are shown in Table I. When compared with other groups, the number of subjects with LBM was higher in the group with the longest duration of breast-feeding ( $p=0.001$ ) (Table I). In bivariate analysis, femur BMD correlated negatively with age $(r=-0.520$, $p<0.001)$, duration of menopause $(r=-0.481$, $p<0.001)$, parity $(r=-0.191, p<0.001)$, and total breast-feeding time $(r=-0.116, p<0.005)$, but positively with BMI $(r=0.318, p<0.001)$ (Figure 1$)$. However, there was no correlation between femur BMD and age of menopause or duration of fertility. Similarly, spine BMD was correlated negatively with age $(r=-0.342, p<0.001)$, duration of menopause $(r=-0.357, p<0.001)$, age at menarche $(r=-0.165$, $p<0.001)$, parity $(r=-0.227, p<0.001)$ and duration of breast-feeding $(r=-0.151, p=0.001)$, but positively with $\mathrm{BMI}(r=0.327, p<0.001)$ and duration of fertility ( $r=0.116, p=0.01$ ) (Figure 1 ). However, there was no correlation between spine BMD and age of menopause. Moreover, in comparisons of femur BMD and spine BMD values of groups, while duration of breast-feeding was increasing, both femur BMD and spine BMD values were decreasing in groups (except group 1, Table I). In contrast, while duration of breast-feeding was increasing, age, BMI, and duration of menopause were also increasing (Table I).

Logistic regression analysis was performed to examine the independent association between duration of breast-feeding and low bone mass according to femur and spine BMD. Significant

Table I. Comparisons of clinical parametres between groups according to total breast-feeding time

\begin{tabular}{|c|c|c|c|c|}
\hline Parameters & Group $1(n=33)$ & Group $2(n=151)$ & Group $3(n=220)$ & Group $4(n=182)$ \\
\hline Age [years] $]^{¥}$ & $56.70 \pm 7.32$ & $57.19 \pm 8.35$ & $60.78 \pm 8.02$ & $64.50 \pm 8.97$ \\
\hline $\mathrm{BMI}\left[\mathrm{kg} / \mathrm{m}^{2}\right]^{\ddagger}$ & $29.15 \pm 4.97$ & $30.21 \pm 5.61$ & $31.52 \pm 5.13$ & $30.98 \pm 5.16$ \\
\hline Time since menopause [years]§ & $10.88 \pm 8.36$ & $11.01 \pm 8.80$ & $13.45 \pm 8.47$ & $17.12 \pm 9.84$ \\
\hline Age of menopause [years] ${ }^{\ddagger}$ & $46.0 \pm 5.37$ & $46.16 \pm 5.09$ & $47.39 \pm 4.89$ & $47.42 \pm 5.50$ \\
\hline Age of menarche [years] ${ }^{\top \pi}$ & $13.42 \pm 1.71$ & $13.74 \pm 1.39$ & $13.89 \pm 1.41$ & $14.22 \pm 1.29$ \\
\hline Reproductive period [years] $]^{\ddagger}$ & $32.58 \pm 4.94$ & $32.37 \pm 5.21$ & $33.43 \pm 5.16$ & $33.20 \pm 5.64$ \\
\hline Parity $(n)^{\dagger}$ & $0.70 \pm 1.31$ & $3.03 \pm 1.46$ & $4.11 \pm 1.80$ & $6.19 \pm 2.25$ \\
\hline Femoral neck BMD $\left[\mathrm{g} / \mathrm{cm}^{2}\right]^{*}$ & $0.814 \pm 0.122$ & $0.846 \pm 0.127$ & $0.819 \pm 0.118$ & $0.805 \pm 0.125$ \\
\hline Lumbar spine BMD $\left[\mathrm{g} / \mathrm{cm}^{2}\right]^{\star *}$ & $0.962 \pm 0.169$ & $0.975 \pm 0.171$ & $0.946 \pm 0.158$ & $0.912 \pm 0.161$ \\
\hline T scoring of femur neck & $-1.25 \pm 1.01$ & $-0.99 \pm 1.04$ & $-1.21 \pm 0.97$ & $-1.34 \pm 1.03$ \\
\hline T scoring of lumbar spine & $-1.40 \pm 1.40$ & $-1.28 \pm 1.42$ & $-1.54 \pm 1.31$ & $-1.82 \pm 1.33$ \\
\hline \multicolumn{5}{|l|}{ BMD groups $₫$} \\
\hline Normal (\%) & $6(18.2)$ & $49(32.5)$ & $45(20.5)$ & $23(12.6)$ \\
\hline Osteopenia (\%) & $17(51.5)$ & $53(35.1)$ & $99(45)$ & $82(45.1)$ \\
\hline Osteoporosis (\%) & $10(30.3)$ & $49(32.5)$ & $76(34.5)$ & $77(42.3)$ \\
\hline
\end{tabular}

" $\chi^{2}$ test for nonparametric variables; $p=0.001$, *significant difference between group 2 and group 4 in post hoc analysis $(p=0.029)$, ${ }^{* *}$ significant difference between group 2 and group 4 in post hoc analysis $(p=0.007)$, "Tsignificant difference between group 1 and group 4 ( $p=0.028)$, group 2 and group $4(p=0.019)$ in post hoc analysis, $¥$ no difference between groups. †significant differences between all groups in post hoc analysis $(p<0.001),{ }^{*}$ significant differences between group 4 and group 1, group 2, and group 3 (all, $p<0.001$ ), between group 3 and group 2 ( $p=0.001$ ), \$significant differences between group 4 and group 1, group 2, and group $3(p=0.004, p<0.001, p=0.001$, respectively) 

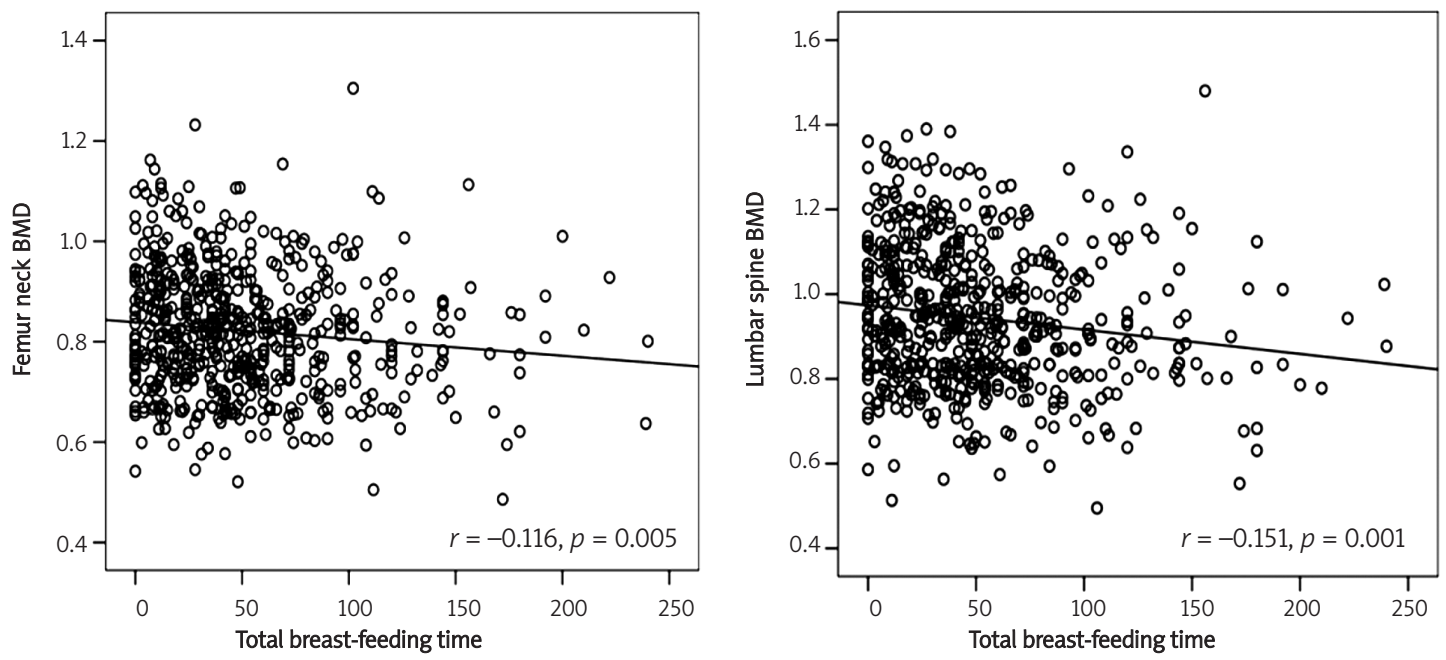

- Observed

- Linear

Figure 1. Total breast-feeding time and femur BMD and spine BMD values in bivariate analysis

parameters obtained from comparisons of BMD groups were included in the logistic regression analysis. Used covariates for analysis are shown in Table II. Independent predictors of low femur BMD were age, body mass index (BMI), age at menarche, and duration of menopause, whereas only BMI was an independent predictor of low spine BMD.
Moreover, in multivariate logistic regression analysis, duration of breast-feeding was not found to be an independent risk factor for low femur BMD or low spine BMD (Table II). Linear regression analysis results were similar to those of logistic regression. Age, $\mathrm{BMI}$, age at menarche, and duration of menopause were independent predictors for

Table II. Independent predictors of low bone mass according to spine or femur BMD values

\begin{tabular}{|c|c|c|c|c|}
\hline \multicolumn{5}{|c|}{ Independent predictors of low bone mass for spine } \\
\hline \multirow[t]{2}{*}{ Predictor } & \multirow[t]{2}{*}{ OR } & \multicolumn{2}{|c|}{$95 \%$ confidence interval } & \multirow[t]{2}{*}{ Value of $p$} \\
\hline & & Lower & Upper & \\
\hline Body mass index & 0.903 & 0.870 & 0.937 & $<0.001$ \\
\hline Age & 1.027 & 0.986 & 1.071 & 0.202 \\
\hline Duration of menopause & 1.034 & 0.995 & 1.075 & 0.086 \\
\hline Physical activity & 0.692 & 0.470 & 1.019 & 0.062 \\
\hline Smoking (package-years) & 0.969 & 0.933 & 1.006 & 0.102 \\
\hline Parity & 1.116 & 0.994 & 1.252 & 0.063 \\
\hline Age at menarche & 1.038 & 0.904 & 1.191 & 0.600 \\
\hline Total breast-feeding time & 0.999 & 0.993 & 1.005 & 0.735 \\
\hline \multicolumn{5}{|c|}{ Independent predictors of low bone mass for femur } \\
\hline \multirow[t]{2}{*}{ Predictor } & \multirow[t]{2}{*}{ OR } & \multicolumn{2}{|c|}{$95 \%$ confidence interval } & Value of $p$ \\
\hline & & Lower & Upper & \\
\hline Age & 1.106 & 1.058 & 1.157 & $<0.001$ \\
\hline Body mass index & 0.893 & 0.859 & 0.930 & $<0.001$ \\
\hline Duration of menopause & 1.048 & 1.007 & 1.090 & $<0.021$ \\
\hline Age at menarche & 1.177 & 1.019 & 1.359 & 0.027 \\
\hline Parity & 1.004 & 0.897 & 1.124 & 0.947 \\
\hline Total breast-feeding time & 0.998 & 0.992 & 1.004 & 0.513 \\
\hline Hypertension & 1.197 & 0.797 & 1.796 & 0.386 \\
\hline
\end{tabular}


Table III. Independent predictors of spine and femur BMD obtained from linear regression analysis

\begin{tabular}{|lccc|}
\hline \multicolumn{4}{|c}{ Independent predictors of low bone mass for spine } \\
\hline Predictor & SE & $\beta$ & Value of $p$ \\
\hline Age & 0.010 & -0.120 & 0.074 \\
\hline Duration of menopause & 0.010 & -0.189 & 0.442 \\
\hline Parity & 0.027 & 0.137 & 0.455 \\
\hline Physical activity & 0.082 & -0.082 & 0.433 \\
\hline Smoking (package-years) & 0.120 & 0.071 & 0.059 \\
\hline Total breast-feeding time & 0.001 & 0.033 & 0.478 \\
\hline Body mass index & 0.009 & 0.309 & $<0.001$ \\
\hline Independent predictors of low bone mass for femur \\
\hline Predictor & SE & $\beta$ & Value of $p$ \\
\hline Age & 0.007 & -0.390 & 0.008 \\
\hline Duration of menopause & 0.007 & -0.140 & 0.019 \\
\hline Parity & 0.018 & -0.155 & 0.340 \\
\hline Total breast-feeding time & 0.001 & 0.80 & 0.064 \\
\hline Body mass index & 0.006 & 0.281 & $<0.001$ \\
\hline Age of menarche & 0.036 & -0.093 & 0.012 \\
\hline
\end{tabular}

femur BMD. Body mass index was the only independent predictor of spine BMD (Table III).

In multinomial regression analyses, age, BMI, age at menarche, and duration of menopause were independent predictors of both osteopenia and osteoporosis in femur. Likewise, BMI was the only predictor for both osteopenia and osteoporosis in spine (Table IV).

\section{Discussion}

In the present study, we investigated the effect of duration of lactation on bone mineral density in postmenopausal women. We found that there was a correlation between the total duration of the lactation period and spine BMD and femur BMD. After dividing the study population into four groups according to breast-feeding duration, the group having the longest lactation period had the lowest spine BMD, spine t score, femur BMD, and femur t score. Additionally, in the groups with lower BMD, age, duration of menopause, age of menarche, and parity were higher but BMI was lower. In multivariate logistic regression analysis, we found that predictors of low femur BMD were age, BMI, age of menarche, and duration of menopause, whereas only BMI was an independent predictor of low spine BMD. Moreover, duration of breastfeeding was not found to be an independent risk factor for low femur BMD or low spine BMD.

The major reproductive events in a woman's life involve complex hormonal changes. The fluctuations in concentrations of endocrine hormones, especially oestrogen, that occur with pregnancy, breast-feeding and menopause also act as potent influences on Ca metabolism and bone metabolism [9, 20-22]. However, the results that have been published from studies on reproductive factors such

Table IV. Independent predictors of osteopenia and osteoporosis in multinomial regression analysis

\begin{tabular}{|c|c|c|c|c|c|c|}
\hline \multicolumn{7}{|c|}{ Independent predictors of osteopenia and osteoporosis for femur BMD in multinomial regression analysis } \\
\hline \multirow[t]{2}{*}{ Predictor } & \multicolumn{3}{|c|}{ Osteopenia } & \multicolumn{3}{|c|}{ Osteoporosis } \\
\hline & OR & $95 \% \mathrm{Cl}$ & Value of $p$ & OR & $95 \% \mathrm{Cl}$ & Value of $p$ \\
\hline Age & 1.096 & 1.048-1.147 & $<0.001$ & 1.201 & $1.122-1.285$ & $<0.001$ \\
\hline Duration of menopause & 1.049 & $1.008-1.092$ & 0.019 & 1.051 & $0.919-0.987$ & 0.011 \\
\hline Age of menarche & 1.149 & $1.029-1.329$ & 0.041 & 1.469 & $1.156-1.868$ & 0.002 \\
\hline BMI & 0.911 & $0.875-0.948$ & $<0.001$ & 0.765 & $0.709-0.825$ & $<0.001$ \\
\hline Parity & 0.969 & $0.861-1.090$ & 0.559 & 1.237 & $0.934-1.453$ & 0.095 \\
\hline Total breastfeeding time & 1.000 & $0.993-1.006$ & 0.886 & 0.989 & $0.979-1.098$ & 0.229 \\
\hline \multicolumn{7}{|c|}{ Independent predictors of osteopenia and osteoporosis for spine BMD in multinomial regression analysis } \\
\hline \multirow[t]{2}{*}{ Predictor } & \multicolumn{3}{|c|}{ Osteopenia } & \multicolumn{3}{|c|}{ Osteoporosis } \\
\hline & OR & $\% 95 \mathrm{Cl}$ & Value of $p$ & OR & $\% 95 \mathrm{Cl}$ & Value of $p$ \\
\hline Age & 0.975 & 0.796-1.194 & 0.805 & 1.130 & $0.930-1.373$ & 0.219 \\
\hline Duration of menopause & 1.066 & $0.872-1.304$ & 0.531 & 0.974 & $0.803-1.182$ & 0.219 \\
\hline Age of menarche & 1.046 & $0.814-1.345$ & 0.725 & 1.032 & $0.803-1.182$ & 0.974 \\
\hline Reproductive period & 1.058 & $0.862-1.298$ & 0.591 & 0.903 & $0.742-1.100$ & 0.807 \\
\hline BMI & 0.935 & $0.899-0.972$ & 0.001 & 0.862 & $0.822-0.903$ & $<0.001$ \\
\hline Parity & 1.098 & $0.972-1.239$ & 0.133 & 1.161 & $0.920-1.321$ & 0.237 \\
\hline Total breastfeeding time & 1.001 & $0.995-1.008$ & 0.751 & 0.998 & $0.991-1.006$ & 0.677 \\
\hline
\end{tabular}


as parity, age at menarche, time since menopause, reproductive period, and BMD are extremely controversial, with some demonstrating a beneficial effect, while others show a detrimental impact of these factors on bone mass [22-28]. In the current study, we have found an independent association between femur BMD and age of menarche and duration of menopause. However, there was not an independent correlation between spine BMD and age of menarche, duration of menopause, parity or the duration of fertility.

Trabecular bone (lumbar spine, os calcis) has been shown to be more sensitive to metabolic changes compared with cortical bone (femoral neck, distal radius) [29]. Furthermore, there are differences in the timing of bone loss in healthy women, with trabecular bone diminishing with every decade of life but cortical bone levels being similar in the third, fourth, and fifth decades [30]. As there are essential differences in response to environmental (including hormonal and nutritional) factors between the cortical (at the femoral neck) and trabecular (lumbar spine) part of the bone structure, similar to our study, it would seem more logical that measurements of both cortical and trabecular bone are necessary.

Similar to our study, Sowers et al. investigated the relation of breast-feeding time and BMD in postpartum women, dividing them into three groups according to their breast-feeding time [31]. They found that women who breast-fed for at least 6 months had significantly different levels of three bone turnover markers and by 18 months of observation there was no difference in the mean values among the three lactation groups. As a result of their study, they showed that differences in the bone-turnover markers in the lactation period were associated with breast-feeding time and menstrual re-activation, rather than age, physical activity, dietary calcium intake or body size. The complete recovery of spine BMD takes 12 months postpartum, and may extend to 18 months for the loss of femur neck BMD. In a large study, Hadji et al. investigated the effects of reproductive factors on BMD parameters measured by quantitative ultrasonometry in 2080 postmenopausal women [16]. They compared women who had never breast-fed with women who had breast-fed and found no difference according to factors affecting BMD such as age, weight, BMI, and time since menopause. Similar to our results, they reported that breast-feeding time had no significant effect on BMD in postmenopausal women. Conversely, in 1486 postmenopausal women, Dursun et al. demonstrated negative correlations between both the lumbar spine and femoral neck BMD values and breast-feeding time [14]. Additionally, they found increased frequency of osteoporosis in women with longer duration of total breast-feeding. As a result, they emphasized that total duration of breast-feeding might be an independent risk factor for osteoporosis in postmenopausal Turkish women. However, in their study, when comparing with the group having a shorter breast-feeding time, there were significant differences in factors such as age, time since menopause, and BMI which affect BMD in groups having a longer breast-feeding time. Nevertheless, they did not perform any methods of regression analysis including these factors for detecting independent predictors. On the other hand, we have determined inverse correlations between breastfeeding time and spine and femur neck BMD in bivariate correlation analysis. Moreover, we have shown that the number of subjects with LBM was higher in the group with the longest duration of breast-feeding. Although our results are mainly in agreement with the findings of Dursun et al., unlike them, we have found that there was no relation between the bone loss and time of breast-feeding in logistic regression analysis. Consequently, this result obtained from regression analysis has confirmed that there is a complex role of numerous factors which affect BMD apart from feeding time.

These conflicting results in previously reported studies might be explained at least in part by different patient selections (such as age, ethnicity, sample size, inclusion of patients with comorbidities), study design, statistical analyses, sites of bone measured, and different diagnostic methods or criteria. In the present study, we followed strict rules in the selection of the study population and in excluding patients with confounding factors such as HRT use, cancer, pulmonary diseases, and coronary artery disease especially affecting bone mass. Additionally, although bone mass was determined by impractical and/or expensive methods in some studies [16], we used measurements of bone mass obtained from DXA which are considered the best non-invasive methods of determining density [32].

Our analysis was restricted to postmenopausal women aged 40 years and older; therefore, our findings are not generalizable to premenopausal women. In addition, because of the cross-sectional design of the study, we are not sure whether low BMD occurred before the menopause. Another limitation of this study is the lack of measurement of vitamin D levels. Therefore, prospective designed studies with a larger sample size including the measurement of biochemical indices of bone mineral metabolism are needed to evaluate in more detail the relationship between total breast-feeding time and BMD.

In conclusion, the present study is the second to evaluate the association between total breastfeeding time and bone mineral density measured by DXA in a large representative sample of postmenopausal Turkish women. Consequently, we 
have shown that women with a longer breastfeeding time had significantly lower bone mass of femur or spine. However, breast-feeding time was not found to be an independent predictor of low bone mass. This may result from complex interactions between other factors affecting BMD rather than solely the effect of feeding time.

\section{References}

1. Yaturu S, Humphrey S, Jain S, Landry C. Decreased bone mineral density in men with metabolic sydrome alone and with type 2 diabetes. Med Sci Monit 2009; 15: CR5-9.

2. Espallargues M, Sampietro-Colom L, Estrada MD, et al. Identifying bone-mass-related risk factors for fracture to guide bone densitometry measurement: a systemic rewiew literature. Osteoporos Int 2001; 12: 811-22.

3. Tang YJ, Huey W, Sheu H, Liu PH, Lee WJ, Chen YT. Positive associations of bone mineral density with body mass index, physical activity, and blood trigylseride level in men over 70 years old: a TCVGHAGE study. J Bone Miner Metab 2007; 25: 54-9.

4. The North American Menopause Society. Management of osteoporosis in postmenopausal women: 2006 position statement of The North American Menopause Society. Menopause 2006; 13: 340-67.

5. Specker BL, Tsang RC, Ho ML. Changes in calcium homeostasis over the first year postpartum: effect of lactation and weaning. Obstet Gynecol 1991; 78: 56-62.

6. Cumming RG, Klineberg RJ. Breastfeeding and other reproductive factors and the risk of hip fractures in elderly women. Int J Epidemiol 1993; 22: 684-91.

7. Aloia JF, Cohn SH, Vaswani A, Yeh JK, Yuen K, Ellis K. Risk factors for postmenopausal osteoporosis. Am J Med 1985; 78: 95-100.

8. Hayslip CC, Klein TA, Wray HL, Duncan WE. The effect of lactation on bone mineral content in healthy postpartum women. Obstet Gynecol 1989; 73: 588-92.

9. Kalkwarf HJ, Specker BL. Bone mineral loss during lactation and recovery after weaning. Obstet Gynecol 1995; 86: 26-32.

10. Kritz-Silverstein D, Barrett-Connor E, Hollenbach KA. Pregnancy and lactation as determined of bone mineral density in postmenopausal women. Am J Epidemiol 1992; 136: 1052-9.

11. Lissner L, Bengtsson C, Hansson T. Bone mineral content in relation to lactation history in pre- and postmenopausal women. Calcif Tissue Int 1991; 48: 319-25.

12. Chowdhury S, Sarkar NR, Roy SK. Impact of lactational performance on bone mineral density in marginallynourished women. J Health Popul Nutr 2002; 20: 26-30.

13. Dursun N, Akin S, Dursun E, Sade I, Korkusuz F. Influence of duration of total breast-feeding on bone mineral density in a Turkish population: does the priority of risk factors differ from society to society? Osteoporos Int 2006; 17: 651-5.

14. Carranza-Lira S, Mera JP. Influence of number of pregnancies and total breast-feeding time on bone mineral density. Int J Fertil Womens Med 2002; 47: 169-71.

15. Hadji P, Ziller V, Kalder M, et al. Influence of pregnancy and breast-feeding on quantitative ultrasonometry of bone in postmenopausal women. Climacteric 2002; 5: 277-85.

16. Jones G, Scott FS. A cross-sectional study of smoking and bone mineral density in premenopausal parous women: effect of body mass index, breast feeding, and sports participation. J Bone Miner Res 1999; 14: 1628-33.

17. Sowers M, Randolph J, Shapiro B, Jannausch M. A prospective study of bone density and pregnancy after an extended period of lactation with bone loss. Obstet Gynecol 1995; 85: 285-9.

18. Hansen MA, Overgaard K, Riis BJ, Christiansen C. Potential risk factors for development of postmenopausal osteoporosis-examined over a 12-year period. Osteoporos Int 1991; 1: 95-102.

19. Chobanian AV, Bakris GL, Black HR, et al.; National Heart, Lung, Blood Institute; National High Blood Pressure Education Program Coordinating Committee. Seventh report of the Joint National Committee on Prevention, Detection, Evaluation, and Treatment of High Blood Pressure. Hypertension 2003; 42: 1206-52.

20. Krebs NF, Reidinger CJ, Robertson AD, Brenner M. Bone mineral density changes during lactation: maternal, dietary, and biochemical correlates. Am J Clin Nutr 1997; 65: $1738-46$

21. McGrowder D, Williams A, Gordon L, et al. Hypocalciuria in pre-eclampsia and gestational hypertension due to decreased fractional excretion of calcium. Arch Med Sci 2009; 5: 80-5.

22. Nguyen TV, Jones G, Sambrook PN, White CP, Kelly PJ, Eisman JA. Effects of estrogen exposure and reproductive factors on bone mineral density and osteoporotic fractures. J Clin Endocrinol Metab 1995; 80: 2709-14.

23. Grainge M, Coupland C, Cliffe S, Chilvers C, Hosking D. Reproductive, menstrual and menopausal factors: which are associated with bone mineral density in early postmenopausal women? Osteoporos Int 2001; 12: 777-87.

24. Parazzini F, Bidoli E, Franceschi S, et al. Menopause, menstrual and reproductive history, and bone density in northern Italy. J Epidemiol Community Health 1996; 50: 519-23.

25. Gur A, Nas K, Cevik R, Sarac AJ, Ataoglu S, Karakoc M. Influence of number of pregnancies on bone mineral density in postmenopausal women of different age groups. J Bone Miner Metab 2003; 21: 234-41.

26. Rosenthal DI, Mayo-Smith W, Hayes CW, et al. Age and bone mass in premenopausal women. J Bone Miner Res 1989; 4: 533-8.

27. Nordin BE, Need AG, Chatterton BE, Horowitz M, Morris $H A$. The relative contributions of age and years since menopause to postmenopausal bone loss. J Clin Endocrinol Metab 1990; 70: 83-8.

28. Vico L, Prallet B, Chappard D, Pallot Prades B, Pupier R, Alexandre C. Contributions of chronological age, age at menarche and menopause and of anthropometric parameters to axial and peripheral bone densities. Osteoporos Int 1992; 2: 153-8.

29. Tsurusaki K, Ito M, Hayashi K. Differential effects of menopaus and metabolic disease on trabecular and cortical bone assessed by peripheral quantitative computed tomography (pQCT). Br J Radiol 2000; 73: 14-22.

30. Buchanan JR, Myers C, Lloyd T, Greer RB III. Early vertebral trabecular bone loss in normal premenopausal women. J Bone Miner Res 1988; 3: 583-7.

31. Sowers MF, Eyre D, Hollis BW, et al. Biochemical markers of bone turnover in lactating and nonlactating postpartum women. J Clin Endocrinol Metab 1995; 80: 2210-6.

32. Black DS, Cummings R, Genant HK, Nevitt MC, Palermo L, Browner W. Axial and appendicular bone density predict fractures in older women. J Bone Miner Res 1992; 7: 633-8. 